\title{
Locus of Control Scale
}

National Cancer Institute

\section{Source}

National Cancer Institute. Locus of Control Scale. NCI Thesaurus. Code C121274.

A rating scale included in the Behavior Assessment System for Children that measures

the subject's belief that rewards and punishment are controlled by external stimulus. 